\title{
Relation between temporal envelope coding, pitch discrimination, and compression estimates in listeners with sensorineural hearing loss
}

\author{
Bianchi, Federica; Santurette, Sébastien; Fereczkowski, Michal; Dau, Torsten
}

Publication date:

2015

Document Version

Publisher's PDF, also known as Version of record

Link back to DTU Orbit

Citation (APA):

Bianchi, F., Santurette, S., Fereczkowski, M., \& Dau, T. (2015). Relation between temporal envelope coding, pitch discrimination, and compression estimates in listeners with sensorineural hearing loss. Poster session presented at 169th Meeting of the Acoustical Society of America, Pittsburgh, Pennsylvania, United States.

\section{General rights}

Copyright and moral rights for the publications made accessible in the public portal are retained by the authors and/or other copyright owners and it is a condition of accessing publications that users recognise and abide by the legal requirements associated with these rights.

- Users may download and print one copy of any publication from the public portal for the purpose of private study or research.

- You may not further distribute the material or use it for any profit-making activity or commercial gain

- You may freely distribute the URL identifying the publication in the public portal 


\section{compression estimates in listeners with sensorineural hearing loss}

Federica Bianchi ${ }^{*}$, Sébastien Santurette ${ }^{1}$, Michal Fereczkowski ${ }^{1}$, Torsten Dau ${ }^{1}$

${ }^{1}$ Hearing Systems, Technical University of Denmark, Ørsteds Plads Building 352, 2800 Kongens Lyngby, Denmark

\section{Introduction}

Recent physiological studies in animals showed that noise-induced sensorineural hearing loss (SNHL) increased the amplitude of envelope coding in single auditorynerve fibers [1, 2]. As pitch coding of unresolved complex tones is assumed to rely on temporal envelope coding mechanisms, the present study investigated pitchdiscrimination performance in listeners with SNHL. Additionally, peripheral loss of compression was considered as a potential factor in envelope coding enhancement. In experiment 1, pitch discrimination was investigated in normal-hearing $(\mathrm{NH})$ and hearing-impaired (HI) listeners for complex tones of varying harmonic resolvability. Envelope processing was assessed in the same listeners in a behavioral amplitudemodulation detection task (experiment 2). Basilar-membrane input/output functions were estimated to assess individual compression ratios (experiment 3).

\section{Method}

口 Participants: $14 \mathrm{NH}$ listeners, $10 \mathrm{HI}$ listeners with SNHL.

Experiment I: Pitch discrimination

- Pitch discrimination of complex tones was measured via difference limens for fundamental frequency $\left(\mathrm{F}_{0} \mathrm{DLs}\right)$.

$\checkmark$ Stimuli: Sine-phase and random-phase complex tones filtered in either a low (LF: 0.3-1.5 kHz) or a high (HF: 1.5-3.5 kHz) frequency region to vary the resolvability of the harmonics [3].

a Paradigm: 3 AFC, two intervals contained a reference complex tone with a fixed $F_{0}$, and one interval contained a deviant complex tone with a larger $F_{0}$.

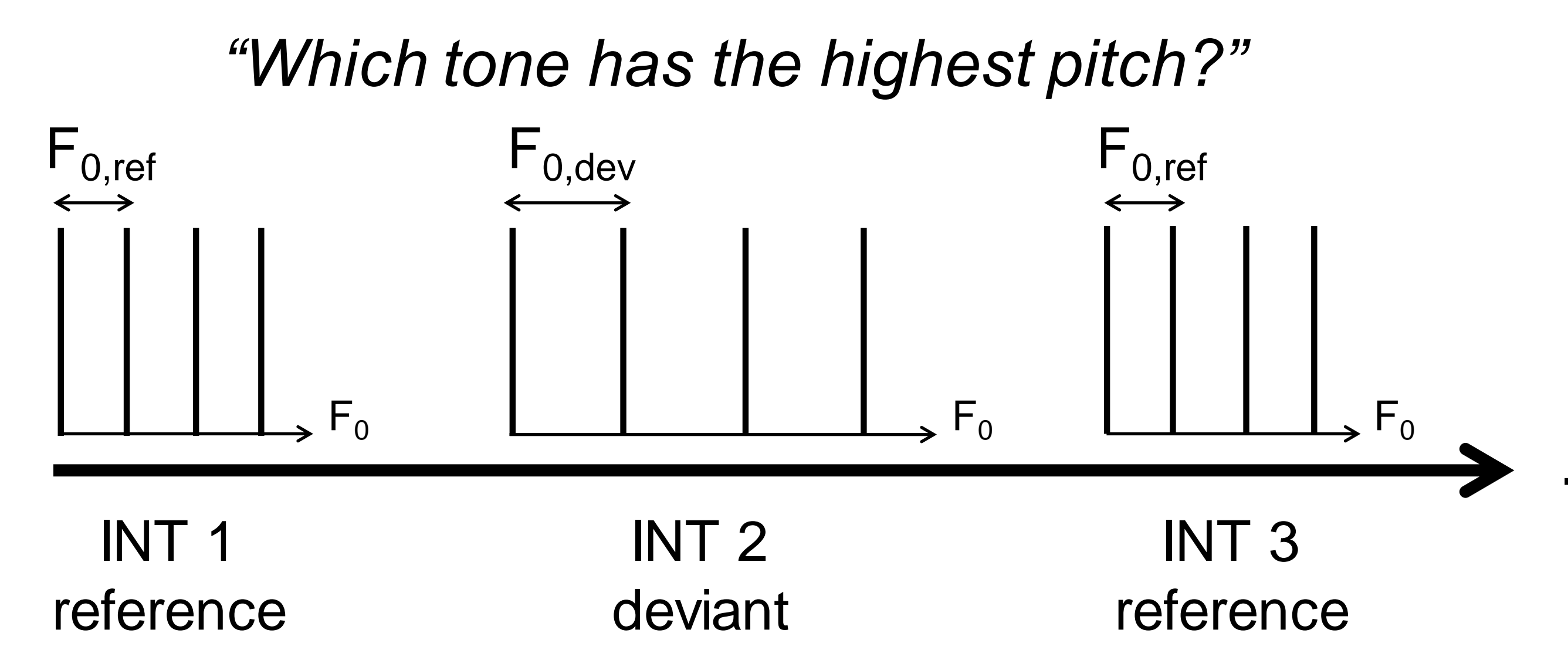

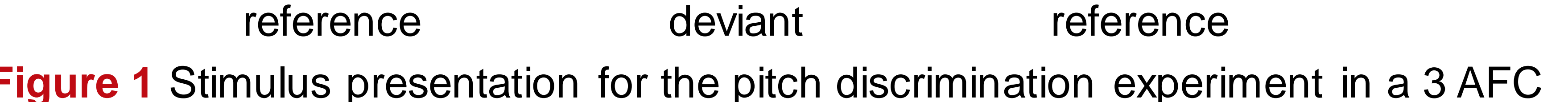
Figure 1 Stimulus presentation for the pilch dischimination expenment in a 3 AFC

Experiment II: Amplitude-modulation detection a Stimuli: Sinusoidal carrier at $2 \mathrm{kHz}$, amplitude modulated at the modulation frequencies $\left(f_{m}\right)$ of $25,50,100,150,200,300,400,500,800,1000,1500 \mathrm{~Hz}$. $\checkmark$ Paradigm: 3 AFC, two intervals contained a pure tone and one interval contained the amplitude modulated tone. The smallest detectable modulation depth $(\mathrm{m})$ was measured as a function of $\mathrm{f}_{\mathrm{m}}$ (i.e., temporal modulation transfer function, $\mathrm{TMTF}$.

Experiment III: Cochlear compression estimates $\checkmark$ Measure temporal masking curves (TMC) and derive basilar-membrane input/output function (BMIO) [4]. प Stimuli: sinusoidal probe at $2 \mathrm{kHz}$ $>$ On-frequency masker: tone at $2 \mathrm{kHz}$ $>$ Off-frequency masker: tone at $1.2 \mathrm{kHz}$. Measure masker level where probe is

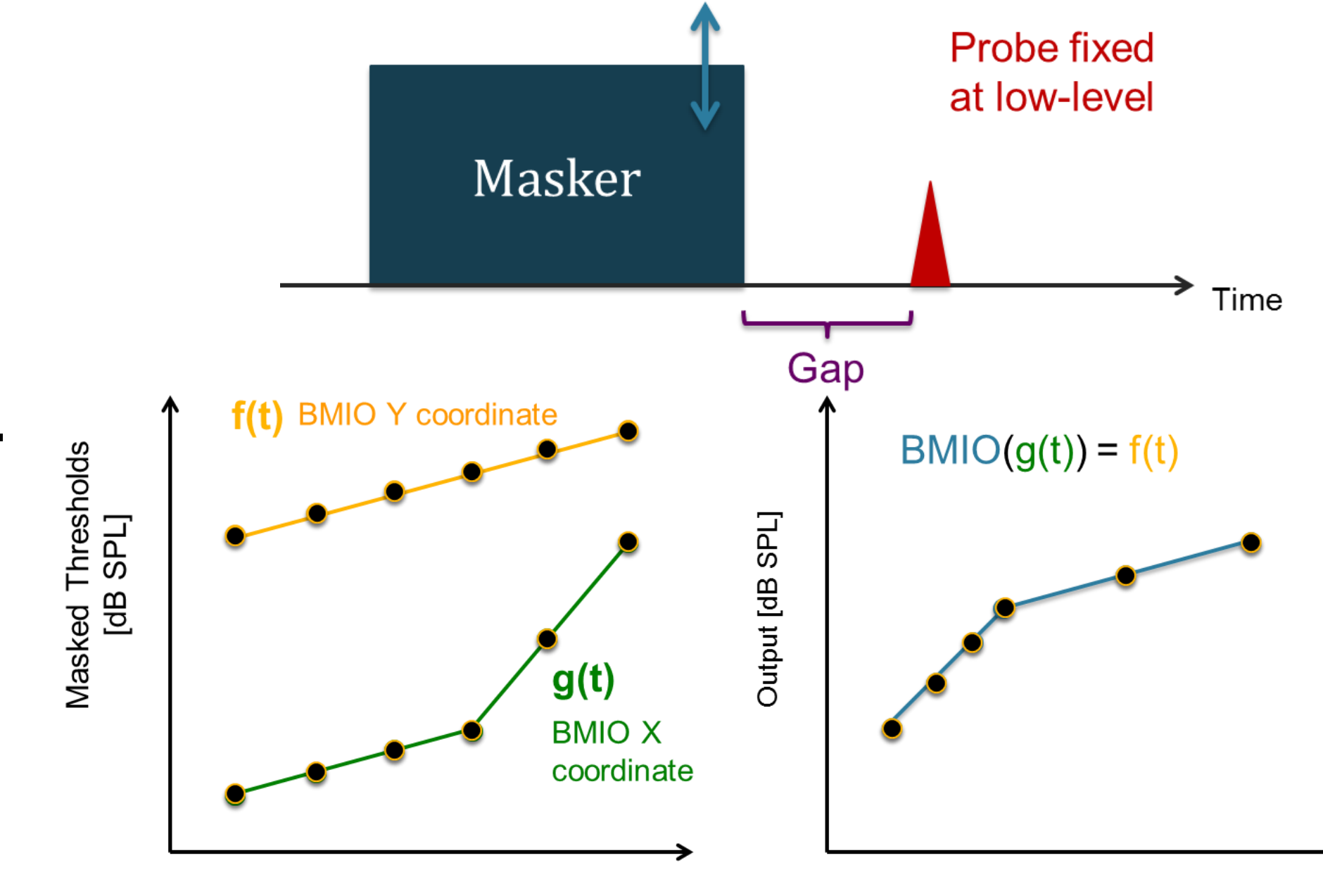
Figure 2 Stimulus presentation for TMC experiment (top panel). Schematics of the TMC (bottom left panel) and derived BMIO (bottom right panel).

\section{Results}

Experiment I: Pitch discrimination $\mathrm{NH}$ listeners (sine phase)

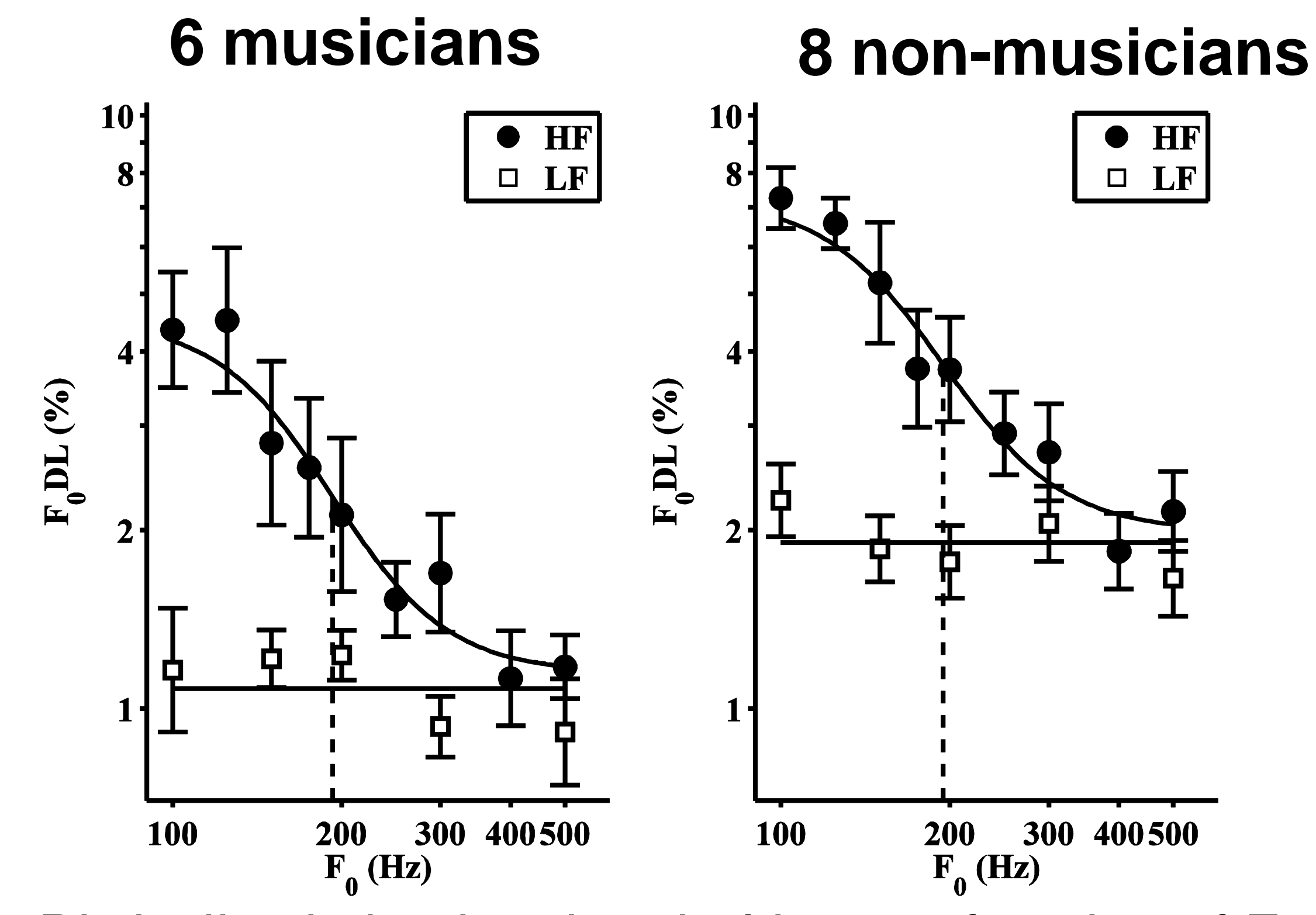

Figure 3 Pitch discrimination thresholds as a function of $F_{0}$ for complex tones filtered either in a low (white squares) or high (black circles) frequency region. Left panel: Musicians, right panel: Non-musicians.

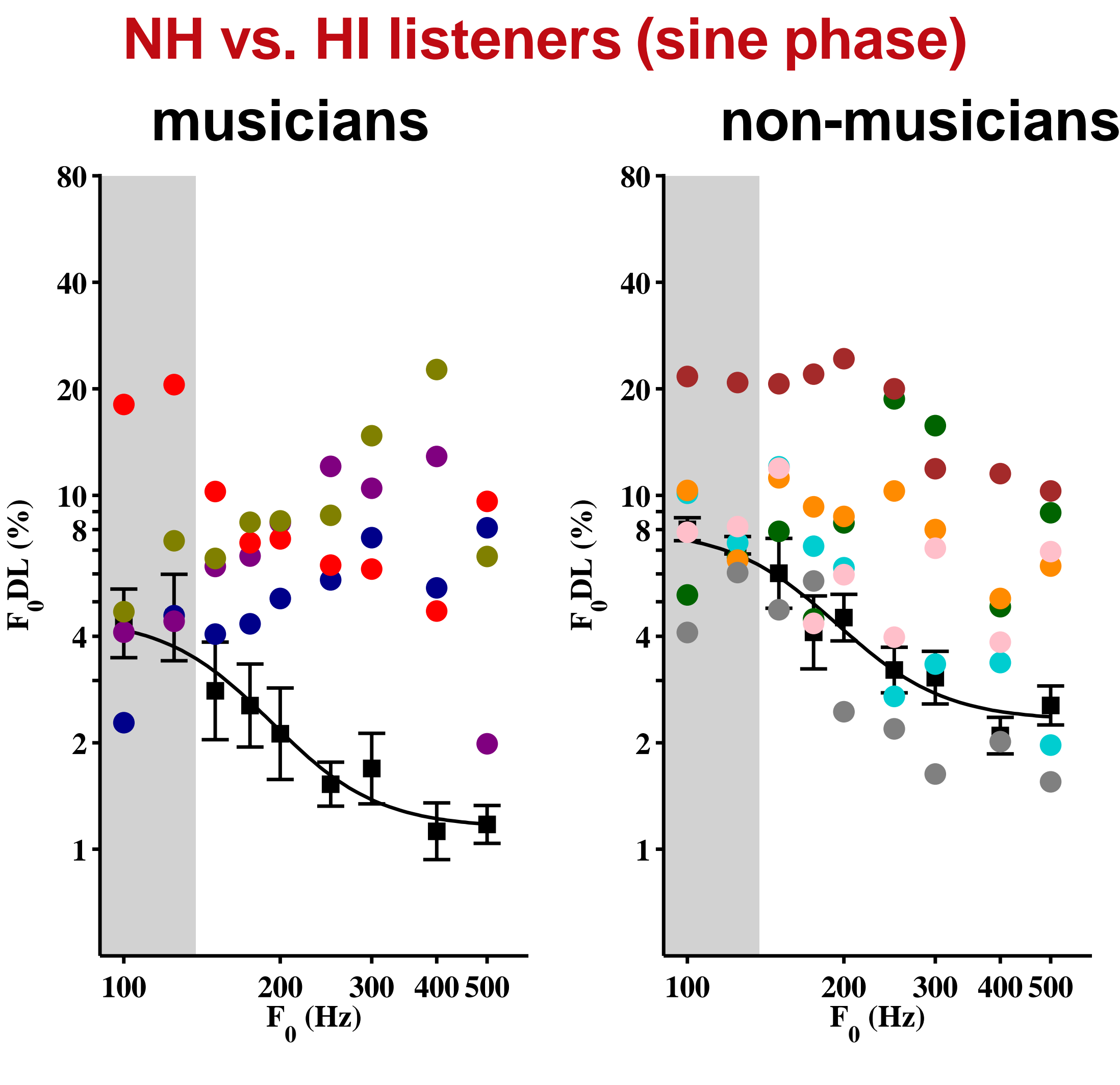

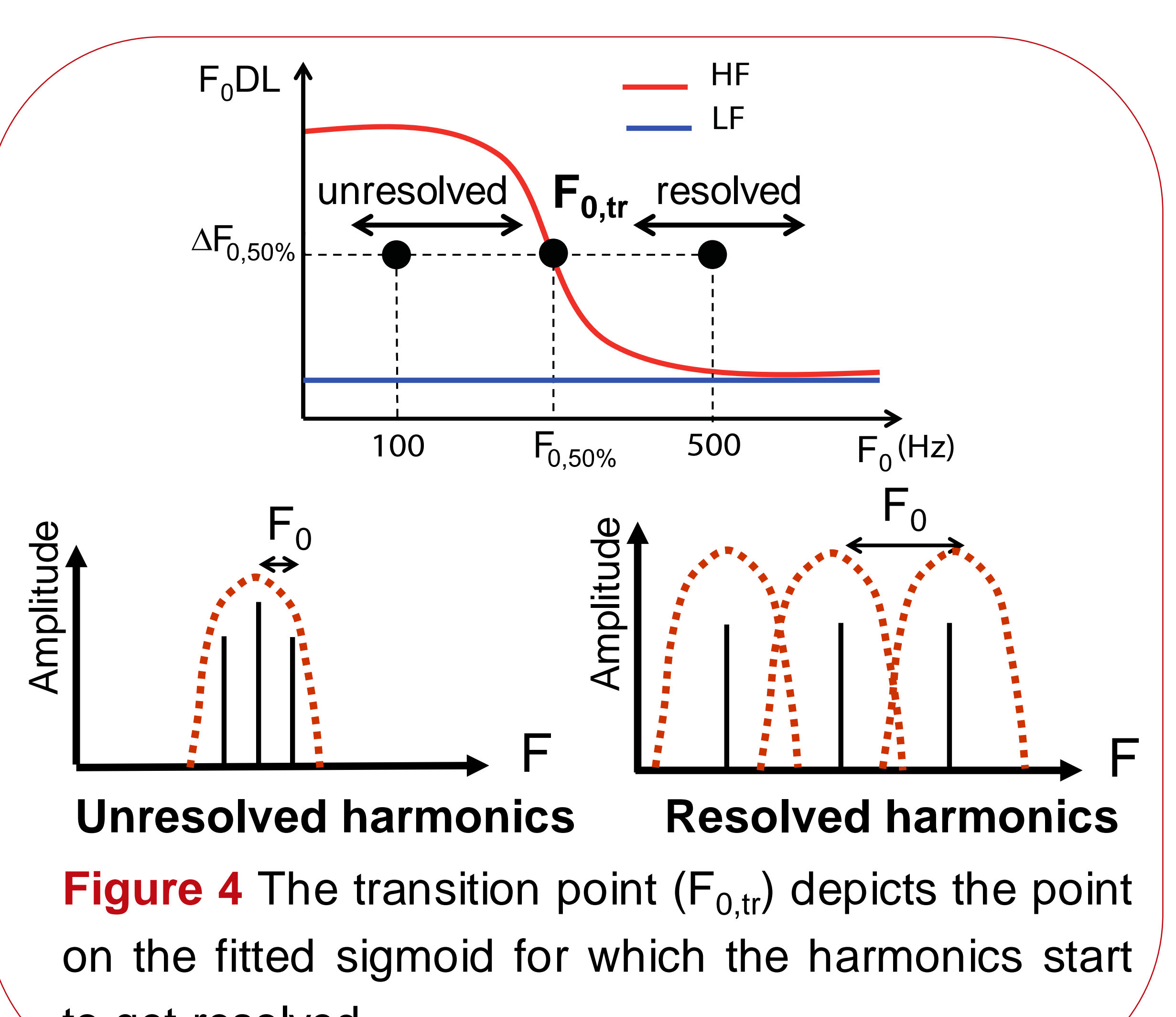

to get resolved.

NH vs. HI listeners (random phase) ${ }_{80}$ musicians $\quad{ }_{80}$ non-musicians
Figure 5 Pitch discrimination thresholds as a function of $\mathrm{F}_{0}$ for $\mathrm{HF}$-filtered complex tones. Black squares: Mean of $\mathrm{NH}$ unresolved for both $\mathrm{NH}$ and $\mathrm{HI}$

$\checkmark$ Pitch-discrimination thresholds were dependent on musical training (see Fig.3) $[5,6,7]$.

- Unresolved conditions (gray-shaded region in Fig.5):

$>8 \mathrm{HI}$ performed as well as $\mathrm{NH}$ for sine-phase complexes

$>6 \mathrm{Hl}$ performed significantly worse than $\mathrm{NH}$ for random-phase complexes. - The ratio between the random-phase and the sine-phase threshold for unresolved complex-tone can be considered as an indicator of envelope

processing that is independent of musical training (see Fig.6).

Experiment II: Amplitude-modulation detection

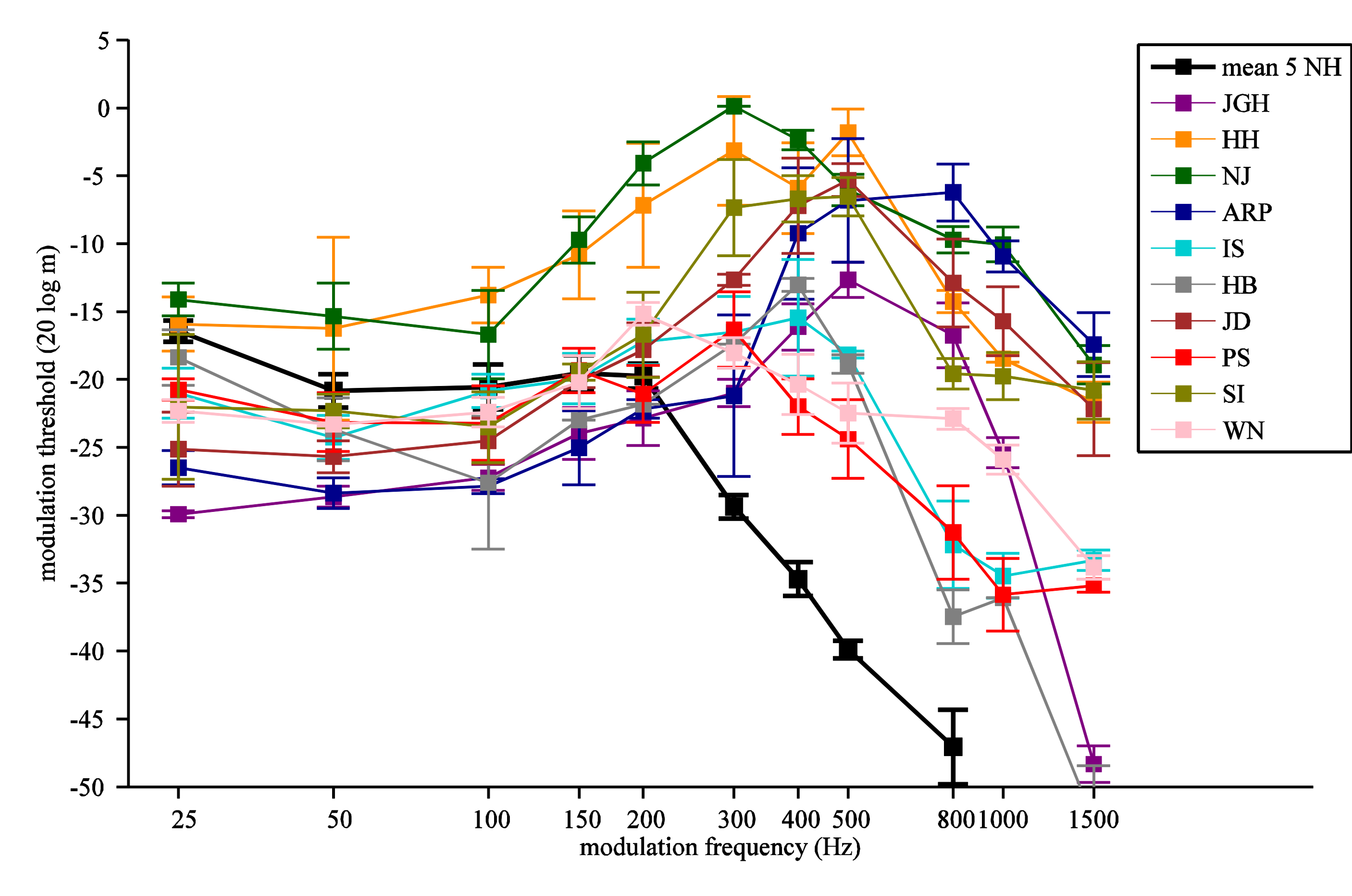

8 Hi listeners showed lower modulation thresholds than $\mathrm{NH}$, when the sidebands were unresolved (i.e., for $\mathrm{f}_{\mathrm{m}}<200 \mathrm{~Hz}$ ).

Auditory filter bandwidth (BW) at $2 \mathrm{kHz}$ was estimated from the TMTF curves (at the $f_{m}$ corresponding to the 10-dB point re. the maximum threshold). squares) and HIl listeners (colored squares).

\section{Discussion}

As pitch-discrimination thresholds were found to depend on musical training, the ratio between random-phase and sine-phase thresholds (FODL ratio in Fig. 6) of unresolved complex-tones was used as an indicator of envelope processing, independent of musical training. Nine $\mathrm{HI}$ listeners showed FODL ratios larger than $\mathrm{NH}$ listeners, suggesting that changes in envelope coding play a role in pitchdiscrimination of unresolved complex tones. Figure 8 shows that there is a trend for the increase of auditory filters bandwidth and loss of cochlear compression to
consistently vary with with the increase of FODL ratios (panels A) and decrease of consistently vary with with the increase of FODL ratios (panels A) and decrease of modulation thresholds (panels B).
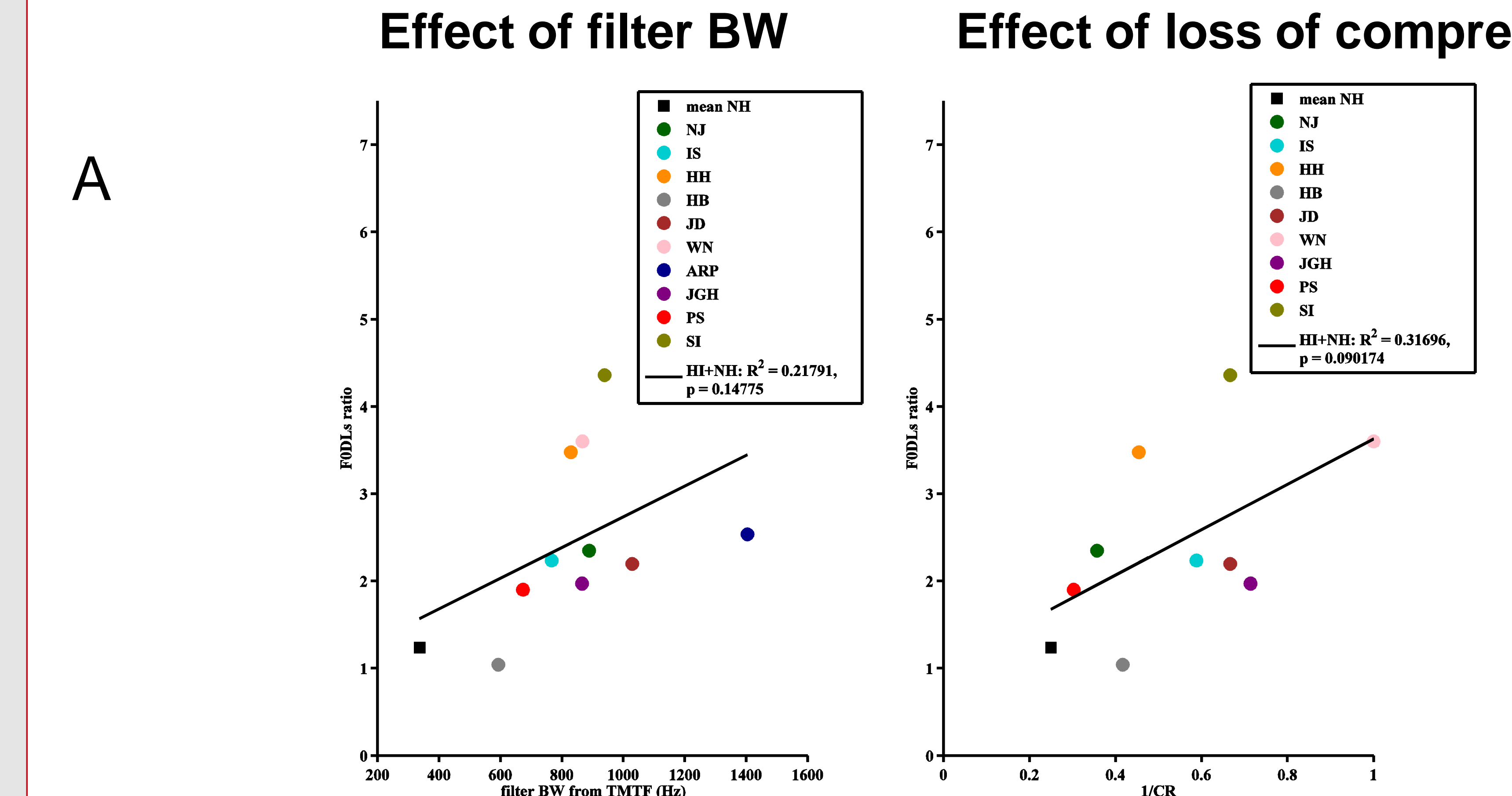

B
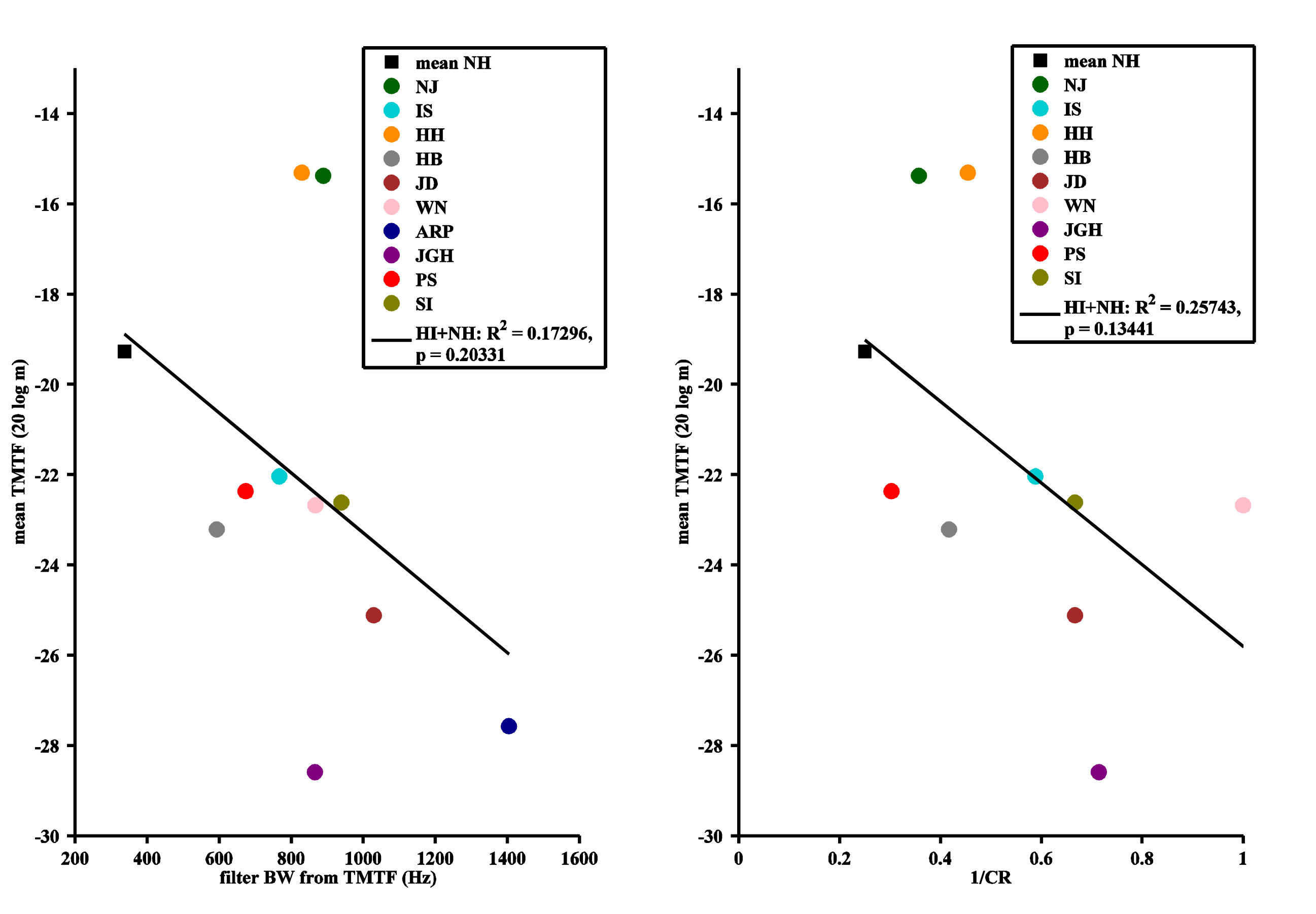

Figure 8 Correlation of FODL ratios (A) and mean TMTF between 25 and $100 \mathrm{~Hz}$ (B) with auditory filter BW estimated from the TMTF curves (left panels) and loss of wh a 8 Cor compression (right panels) for $\mathrm{NH}$ listeners (black square) and $\mathrm{H}$ listeners (colored circles).

\section{Conclusions and perspectives}

Overall, these findings suggest that changes in temporal envelope coding in $\mathrm{HI}$ listeners affect pitch discrimination of unresolved complex tones. Such changes seem to be partly ascribed to auditory filters broadening and loss of cochlear compression. Future modeling work will consider the effects of degraded frequency selectivity and loss of compression on the modulation power at the output of the auditory filters to clarify how each factor contributes to pitch-discrimination performance in $\mathrm{HI}$ listeners. References:

Figure 7 Amplitude-modulation thresholds for $\mathrm{NH}$ (black

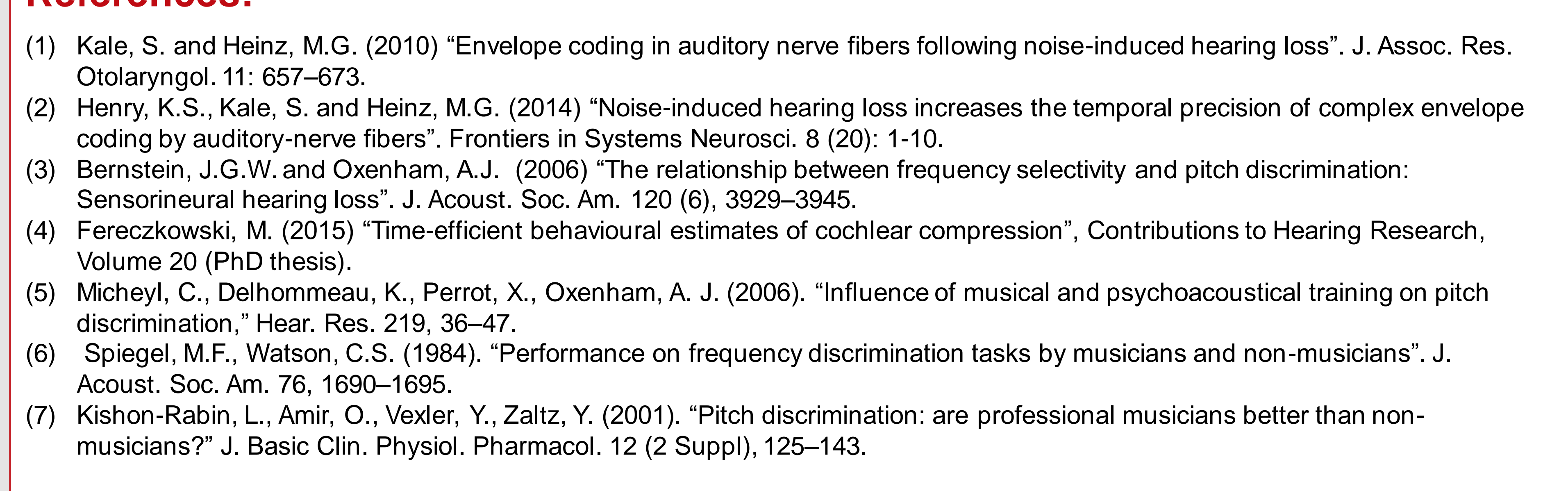

